\title{
A CARTA A MESLAND DE 9 DE FEVEREIRO DE 1645: TRADUÇÃO E COMENTÁRIOS
}

\author{
Geisa Mara Batista* \\ geisamar@yahoo.com \\ Daniel Carrara** \\ dpcarrara@hotmail.com
}

\section{Descartes [ao P. Mesland]}

[Egmond, 09 de fevereiro de 1645]

\section{In: AT IV, p. 173-175}

Quantum ad arbitrij libertatem, planè assentior ijs quae hîc a Reuerendo Patre scripta sunt. Atque vt meam opinionem planiùs exponam, in ijs notari velim indifferentiam mihi videri proprie significare statum illum in quo est voluntas, cùm a nullâ veri vel boni perceptione in vnam magis quàm in aliam partem impellitur; sicque a me sumptam esse, cùm scripsi infimum esse gradum libertatis, quo nos ad ea, ad quae sumus indifferentes, determinemus. Sed fortasse $a b$ alijs per indifferentiam intelligitur positiua facultas se determinandi ad vtrumlibet e duobus contrarijs, hoc est ad profequendum vel fugiendum, affirmandum vel negandum. Quam positiuam facultatem non negaui esse in voluntate. Imo illam in eâ esse arbitror, non modò ad illos actus ad quos a nullis euidentibus rationibus in vnam partem magis quàm in aliam impellitur, sed etiam as alios omnes; adeo vt, cum valde euidens ratio nos in vnam partem mouet, etsi, moraliter loquendo, vix possimus in contrariam

* Bolsista CNPq - Brasil. Mestre em Filosofia pela UFMG.

** Mestre em Estudos Clássicos pela UFMG. 
Ferri, absolutè tamen possimus. Semper enim nobis licet nos reuocare a bono clarè cógnito prosequendo, vel a perspícua veritate admittendâ, modò tantum cogitemus bonum libertatem arbitrij nostri per hoc testari.

Notandum etiam libertatem considerari posse in actionibus voluntatis, vel antequan eliciantur, vel dum eliciantur.

Et quidem spectata in ijs, antequan eliciantur, inuoluit indifferentiam fecundo modo sumptam, non autem primo modo. Et quamuis, opponentes iudicium proprium imperijs aliorum, dicamus nos esse magis líberos ad ea facienda de quibus nihil nobis ab alijs praescribitur, \& in quibus iudicium proprium sequi licet, quàm ad ea quae nobis prohibentur, non ita tamen, iudicia nostra, siue cognitiones nostras vnas alijs opponendo, dicere possumus nos esse magis líberos ad ea facienda quae nec bona nec mala esse nobis videntur, vel in quibus multas quidem rationes boni, sed totidem alias mali cognoscimus, quàm ad ea in quibus multò plus boni quàm mali percipimus. Maior enim libertas consistit vel in maiori facilitate se determinandi, vel in maiori vsu positiuae illius potestatis quam habemus, sequendi deteriora, quamuis meliora videamus. Atqui si sequamur illud, in quo plures rationes boni apparent, faciliùs nos determinamus; si autem oppositum, magis vtimur istâ positiuâ potestate; sicque semper agere possumus magis liberè circa ea in quibus multò plus boni quàm mali percipimus, quàm circa illa quae vocamus $3 \propto \delta ı \propto \phi \circ \rho \alpha$, siue indifferentia. Hocque etiam sensu, ea quae nobis $\mathrm{ab}$ alijs imperantur, \& absque hoc spontè non essemus facturi, minus liberè facimus, quàm quae non imperantur; quia iudicium, quòd illa factu difficilia sint, opponitur iudicio, quòd bonum sit facere quae mandata sunt; quae duo iudicia, quò magis aequaliter nos mouent, tantò plus indifferentiae primo modo sumptae in nobis ponunt.

Libertas autem spectata in actionibus voluntatis, eo ipso tempore quo eliciuntur, nullam indifferentiam, nec primo nec secundo modo sumptam, inuoluit; quia quod fit, non potest manere infectum, quandoquidem fit. Sed consistit in sola operandi facilitate; atque tunc liberum, \& spontaneum, \& voluntarium plane idem sunt. Quo sensu scripsi me eò liberius ad aliquid ferri quò a pluribus rationibus impellor; quia certum est voluntatem nostram maiori tunc cum facilitate atque impetu se mouere.

\section{Tradução}

Quanto à liberdade de arbítrio, concordo inteiramente com as coisas que, neste momento, foram escritas pelo Reverendo Padre. Mas para que eu exponha mais claramente a minha opinião, gostaria que, nessas coisas, fosse 
notado que a indiferença me parece indicar propriamente aquele estado em que se encontra a vontade quando não é impelida, por nenhuma percepção do verdadeiro e do bom, para uma parte mais do que para a outra; e assim foi por mim considerada, quando escrevi que o grau de liberdade por que nos determinamos nos assuntos a que somos indiferentes é o mais baixo. Mas talvez, por outros, a indiferença seja entendida como uma faculdade positiva de se determinar a qualquer de dois contrários, isto é, a perseguir ou evitar, afirmar ou negar. Não neguei existir essa faculdade positiva na vontade. Ao contrário, julgo aquela existir nesta, não somente para aqueles atos aos quais, por nenhuma razão evidente, é impelida para uma parte mais do que para a outra, mas também para todos os outros; de tal maneira que, quando uma razão assaz evidente nos move para uma parte, ainda que, moralmente falando, dificilmente possamos ser levados para a contrária, absolutamente falando, contudo, nós o podemos. De fato, sempre nos é permitido afastarmonos do bem claramente conhecido a ser buscado, ou da transparente ${ }^{i}$ verdade a ser admitida, somente se pensarmos um bem atestar a liberdade do nosso arbítrio através dele. ${ }^{\text {ii }}$

Deve-se notar também que a liberdade pode ser considerada, nas ações da vontade, ou antes que sejam cumpridas ou enquanto são cumpridas.

E, na verdade, observada nelas antes que sejam cumpridas, a liberdade envolve a indiferença considerada do segundo modo, não, contudo, do primeiro. E, embora, opondo nosso próprio juízo aos comandos dos outros, digamos que somos mais livres para fazer as coisas sobre as quais nada nos é prescrito pelos outros, e nas quais é permitido seguir nosso próprio juízo, do que para fazer aquelas que nos são proibidas, não podemos, contudo, dizer, da mesma forma, opondo nossos juízos ou nossas únicas concepções aos outros, que somos mais livres para fazer as coisas que nem boas nem más nos parecem, ou nas quais, em verdade, conhecemos muitas razões do bem mas outras tantas do mal, do que para aquelas em que percebemos muito mais do bem do que do mal. Com efeito, uma maior liberdade consiste ou numa maior facilidade de se determinar, ou num maior uso desse poder positivo que possuímos de seguir coisas piores, embora vejamos as melhores. Mas, se seguimos aquilo em que aparece um maior número de razões do bem, determinamo-nos mais facilmente; se, todavia, seguimos o oposto, usamos mais esse poder positivo;

Outras acepções para o termo: perlúcida, claramente visível, conspícua, evidente, lúcida, clara. [N.T.].

i N.T.: Aqui, procurou-se preservar a ambigüidade inerente ao texto cartesiano. O termo hoc é um neutro que pode se referir tanto ao termo arbitrij [arbítrio] quanto ao termo bonum [bem]. Contudo, pautados na leitura das outras versões da carta, acreditamos que o termo hoc se refere ao termo arbitrij. [N.T.]. 
e assim sempre podemos agir mais livremente acerca de coisas em que percebemos muito mais de bem do que de mal, do que acerca daquelas que chamamos de $3 \propto \delta ı \propto \phi о \rho \propto$, ou indiferentes. E também nesse sentido, as coisas que nos são ordenadas pelos outros, e sem o que não haveríamos de fazer espontaneamente, nós as fazemos de maneira menos livre do que aquelas que não são ordenadas; porque o juízo segundo o qual aquelas são as coisas mais difíceis de se fazer se opõe ao juízo segundo o qual é bom fazer as coisas que foram mandadas; esses dois juízos, quanto mais uniformemente nos movem, tanto mais da indiferença considerada do primeiro modo edificam em nós.

A liberdade, todavia, vista nas ações da vontade, no mesmo tempo em que são cumpridas, não envolve nenhuma indiferença, nem do primeiro nem do segundo modo; porque o que se faz não pode permanecer inacabado, visto que está feito. Mas a liberdade consiste na única facilidade de agir; e, então, o livre e espontâneo e voluntário são nitidamente o mesmo. Nesse sentido, escrevi que sou levado tanto mais livremente a alguma coisa quanto sou impelido por muitas razões; porque é certo que a nossa vontade se move então com maior facilidade e ímpeto.

\section{Um texto problemático de Descartes e seus intérpretes}

Geisa Mara Batista

O pequeno fragmento, supostamente ${ }^{1}$ considerado parte da carta de 09 de fevereiro de 1645 que Descartes escreve ao Padre Mesland, dispensa apresentações para os estudiosos cartesianos. Mesmo aqueles que não são especialistas certamente já ouviram falar do seu teor e da sua importância. Em poucas palavras, diríamos que, nessa carta, Descartes afirma que a indiferença existe mesmo diante da evidência, o que seria contraditório à afirmação do assentimento irresistível ao conhecimento claro e distinto, isto é, à tese presente na Quarta meditação quando da definição da liberdade em seu mais alto grau.

1 Apesar de esse famoso extrato possuir outras duas versões (La Hire, carta 41; Poirier, carta 35) segundo as quais seu destinatário seria Mersenne, comumente os pesquisadores seguem a classificação da biblioteca de Mazarine, que o apresenta como sendo uma continuação da carta de 09 de fevereiro de 1645, escrita ao Padre Mesland. A este respeito, contamos com a contribuição do professor Enéias Forlin (UNICAMP). 
Todavia, para Lívio Teixeira, ${ }^{2}$ a carta representa uma oportunidade para Descartes explicar seu pensamento. Enquanto os jesuítas identificam indiferença a livre-arbítrio, logo em seu início, a carta propõe a distinção entre dois sentidos do termo indiferença (AT, IV, p. 173, 1. 1-17): a indiferença tomada em sentido negativo se refere ao estado em que a vontade não percebe de maneira evidente o bem ou a verdade; e a indiferença tomada em sentido positivo se refere a certa força positiva da vontade presente em todos os momentos de suas escolhas. Descartes então nos esclarece que a indiferença da qual tratou ao longo de sua Quarta meditação é a de caráter negativo, logo, qualquer aparente contradição não seria nada além de uma questão terminológica. A indiferença tomada positivamente refere-se ao próprio poder de escolha, "de tal maneira que, quando uma razão assaz evidente nos move para uma parte, ainda que, moralmente falando, dificilmente possamos ser levados para a contrária, absolutamente falando, contudo, nós o podemos. De fato, sempre nos é permitido afastarmo-nos do bem claramente conhecido a ser buscado, ou da verdade evidente a ser admitida, se pensarmos ser um bem atestar por isso a liberdade do nosso arbítrio" (AT, p. 173, 1. 17-23). Para Lívio Teixeira, essa afirmação "vai no sentido de atribuir à vontade no homem, não primazia absoluta, é certo, mas uma prioridade que consiste na afirmação do caráter ativo da vontade e passivo do entendimento; no caráter formalmente ilimitado da vontade e limitado do entendimento", ${ }^{3}$ o que confirmaria a Quarta meditação.

Contudo, a partir dessa afirmação cartesiana, importantes comentadores, entre os quais Michele Beyssade, ${ }^{4}$ afirmam que tal carta marca uma mudança real no pensamento de Descartes, que gradativamente privilegia a noção de liberdade como livre-arbítrio, em detrimento de uma noção de liberdade como assentimento inevitável e espontâneo às idéias claras e distintas, ou ainda, como dirá Ferdinand Alquié, ${ }^{5}$ trata-se de uma teoria em que "ao homem pensante e racional se opõe o homem livre", o que nos traz o "caráter trágico" dessa correspondência.

Alquié dirá ainda que Laporte, que não corrobora a sua posição, distingue a liberdade positiva - presente na carta - da liberdade esclarecida - da qual trata a Quarta meditação - e a confunde com a "atenção do espírito". Para Laporte, o julgamento é determinado pelas razões que nos levam a julgar,

2 TEIXEIRA, 1990.

3 TEIXEIRA, 1990, p. 67.

4 Cf. BEYSSADE, Michelle. Descartes'doctrine of freedom: diferences between the french and latin texts of forth meditation. In: COTTINGHAM (Ed.)., 1994.

5 ALQUIÉ, 1950, p. 289. 
mas a atenção se exerce sobre as razões e não é, pois, determinada por elas. Se a idéia clara conquista, necessariamente, nosso julgamento, contudo, a atenção é a condição da evidência, e, de posse dessa condição, ela pode evitar o assentimento, "parando de enviar as razões que a tornam evidente". Logo, o que faz nosso julgamento livre é a atenção do espírito, ou, aqui, o poder da vontade de não escolher o evidente. Porém, para Alquié, a tese de Laporte tende a confundir nosso poder positivo de nos dirigir em direção ao nada com a indiferença negativa, enquanto nos permite ignorar o verdadeiro. Para tanto, ele nos lembra que no conteúdo da carta não está exposto apenas um impedimento à adesão esclarecida, mas a recusa voluntária do bem, ou seja, a recusa supõe o conhecimento do bem (ALQUIÉ, 1950, p. 292). A liberdade da vontade implica, pois, a vontade ser sempre positivamente indiferente e, em sua essência, a segunda definição de liberdade de indiferença diz respeito a poder positivo de determinação mesmo diante de razões, e não só na falta delas. Assim, "a carta de 9 de fevereiro, longe de reaproximar as duas indiferenças, as opõe radicalmente". ${ }^{6} \mathrm{E}$ o impasse continua.

Gilson, ao tratar da supressão da crítica à liberdade de indiferença nos Princípios, dando-nos o contexto histórico, fala do interesse nas tentativas de Descartes quanto à aprovação de seus escritos ora pelos doutores da Sorbonne, ora pelos jesuítas, a fim de alcançar seus objetivos de substituir a física aristotélica na Escola. ${ }^{7}$ Tal relato torna quase irresilível a aproximação dos dois temas: se há uma mudança no pensamento cartesiano retratada nesta carta, somos levados ao menos a supor que tal carta poderia também fazer parte de um tipo de estratégia cartesiana para "alisar as arestas", e dizer ao Padre que: "quanto à liberdade do arbítrio, concordo inteiramente com as coisas que, nesse momento, foram escritas pelo Reverendo Padre". Mas tratase de um exercício especulativo.

Ao lado de Laporte e Lívio Teixeira, Pierre Guenancia achará que não se trata aqui de um desvio na doutrina cartesiana. Para Guenancia, a carta não derruba a perspectiva desenhada na Quarta meditação, porque "Descartes escreve também que, recusando-se a admitir uma verdade ou a perseguir um bem claramente conhecido, nós pensamos que é um bem afirmar por isso o nosso livre-arbítrio. E, de fato, para Descartes a liberdade é o maior bem próprio ou a principal perfeição do homem", ${ }^{8}$ o que foi estabelecido na

6 ALQUIÉ, 1950, p. 292.

7 Acerca da preocupação cartesiana com a aprovação dos jesuítas, cf. GILSON, 1913. O trecho acima se refere às páginas 316-336.

8 GUENANCIA, 2000. p. 232. 
Quarta meditação. ${ }^{9}$ A carta a Mesland, então, refere-se a um poder absoluto de escolher: a vontade, de posse da indiferença positiva, pode não julgar a favor da evidência. Mas nota-se que Descartes escreve: isso ocorre com a única condição de pensarmos ser bom atestar desse modo a liberdade de nosso arbítrio (AT IV, p. 173, 1. 22-23). Ou seja, é somente porque está diante de um outro bem, o próprio bem de atestar o livre-arbítrio, que a vontade o escolhe em detrimento de uma evidência qualquer. Logo, nesta concepção, a vontade ainda está seguindo o que lhe é apresentado como um bem, e julga sem nenhuma indiferença negativa.

Como vemos, a leitura da carta e o tipo de relação que estabelece com outros escritos cartesianos estão longe de uma unanimidade. Todavia, não nos restam dúvidas sobre um ponto: o estudo da liberdade em Descartes nos coloca diante de um grande projeto de complexa engenharia cuja principal genialidade é a de reconhecer os fatos da experiência - sendo esse reconhecimento feito, algumas vezes, em detrimento da clareza do entendimento. ${ }^{10}$ Nesse construto a presente carta é um elo de passagem fundamental.

\section{Instrumentos de trabalho}

COLEÇÃO Os Pensadores. Trad. J. Guinsburg. São Paulo: Abril S.A., 1973. DESCARTES. Correspondance: julho 1643-abril 1647. Ed. Adam et Tannery. Paris: Vrin, 1989. 4v.

DESCARTES. Correspondance: janeiro 1640-junho 1643. Ed. Adam et Tannery. Paris: Vrin, 1988. 3v.

DESCARTES. Meditationes de prima philosophia. Ed. Adam-Tannery. Paris, 1902. $7 \mathrm{v}$.

DESCARTES. Les principes de la philosophie. Ed. Adam-Tennery: Paris, 1904. 9v.

9 Também por nossa parte, como é mais bem explicitado em nossa dissertação intitulada Deus e a Física Mecanicista como desafios à questão da liberdade humana em Descartes e realizada sob a orientação da Profa. Dra. Telma Birchal, não contrapomos a carta a Mesland à IV meditação, pois o que está em jogo continua a ser uma vontade que assente àquilo que lhe é apresentado como um bem. Descartes não deixa de fazer uma escolha por uma verdade evidente, pois apenas diante da consideração do testemunho do livre-arbítrio, que é verdade per se nota, a postura é autorizada. Tratar-se-ia, pois, de uma mesma doutrina. Aqui, portanto, observamos que também em outras passagens da obra cartesiana é apontado o caráter de evidência do livre-arbítrio: "A liberdade do arbítrio se conhece por si. Que há liberdade em nossa vontade e podemos assentir ou não assentir segundo nosso arbítrio a muitas coisas, está tão manifesto que deve contar-se entre as noções primeiras e mais conhecidas, que nos são inatas" (Princípios, I, art. 39); "[...] estamos tão conscientes da liberdade e da indiferença que existe em nós, que nada há que compreendamos com inteligência mais cabal” (Princípios, I, art. 41). Assim, não se nega a evidência da primeira verdade, mas antes se reafirma o outro bem, a liberdade do arbítrio.

10 "[...] percebemos clara e distintamente que existe um Deus, mas não o compreendemos bastante para ver como deixa indeterminadas as livres ações dos homens [...] Seria, por conseguinte, absurdo, por não compreender uma coisa, que por sua natureza sabemos que nos deve ser incompreensível, duvidar de outra que compreendemos intimamente e comprovamos em nós mesmos" (Princípios, loc. cit). 
DESCARTES. Meditationes metaphysiques. Paris: GF-Flammarion, 1979.

ALQUIÉ, F. A filosofia de Descartes. Lisboa: Presença, 1993.

ALQUIÉ, F. La Découverte métaphysique de l'homme chez Descartes. Paris: PUF, 1950.

COTTINGHAM, J. (Ed.). Reason, Will and Sesation. Oxford: Clarendon Press, 1994.

FARIA, E. Gramática superior da Língua Latina. Rio de Janeiro: Livraria Acadêmica, 1958.

GILSON, E. La liberté chez Descartes et la Thálogie. Paris: Librairie Félix Alcan, 1913.

GUENANCIA, P. Lire Descartes. Paris: Gallimard, 2000.

LATIN DICIONARY OXFORD. Ed. P. G. W. Glare. New York: Oxford Unifersity Press, 1994.

SANTOS, F. R. dos Santos. Novíssimo dicionário Latino-Português. 11. ed. Belo Horizonte: Garnier, 2000.

TEIXEIRA, L. Ensaio sobre a moral de Descartes. São Paulo: Secretaria do Estado de Cultura: Brasiliense, 1990. 